\title{
EVALUATION OF SHEAR STRENGTH OF MODEL ROCK JOINTS BY EXPERIMENTAL STUDY
}

\author{
G Budi ${ }^{1}$, K.U.M. Rao ${ }^{2}$, Debasis Deb ${ }^{3}$ \\ ${ }^{1}$ Assistant professor, Department of Mining Engineering, Indian School of Mines, Dhanbad, Jharkhand, India \\ ${ }^{2}$ Professor, Department of Mining Engineering, Indian Institute of Technology Kharagpur, West Bengal, India \\ ${ }^{3}$ Professor, Department of Mining Engineering, Indian Institute of Technology Kharagpur, West Bengal, India
}

\begin{abstract}
In this paper, variation of the shear strength of artificial rock joints under constant normal loading condition is studied. Idealised joint surfaces were prepared using a developed molding method with special mortar and shear tests were performed on these samples under CNL conditions. Different levels of normal load and shear displacement were applied on the samples to study joint behaviour before and during considerable relative shear displacement. Nine types of saw-tooth joints have been selected for simplicity of modelling to quantify the effect of CNL conditions on joint shear behaviour. It was found that the shear strength of joints is related to rate of shear displacement, joint roughness (varying joint asperity angles) and applied normal stress condition. Finally, based on the experimental results and observations made of sheared joint samples, a new peak shear strength envelope is proposed to model sawtooth type joints tested under CNL conditions.
\end{abstract}

Keywords: shear strength, artificial rock joints, direct shear test, constant normal loading, peak shear strength

\section{INTRODUCTION}

The stability of underground mine excavations, tunnels, open pit slopes and others in a jointed rock mass is influenced by the shear-strength characteristics of the joints. It is imperative that discontinuities, such as joints, faults, fractures etc., reduce the shear strength of rock mass $[1,2]$. When an excavation is made in a rock mass, primary rock movements take place along the existing joints due to stress relief and associated stress re-distribution. Joints, being generally weaker than the intact rock, can accommodate only a small amount of deformation before slipping. Excessive slippage along the joints and faults may have serious consequences on the excavation stability. Therefore, it is important to quantify the shear-strength of rock joints in the design and construction of engineering structures in rock for sound understanding of the basic mechanics of shear failure. This requires an understanding of the factors that influence the shear-strength characteristics of a rock mass. In view of the importance of the stability of jointed rock slopes and underground rock structures, irrespective of the purpose for which they are made, the focus of the present investigation has been laid on determining the shear-strength characteristics of saw-tooth type of joints. The extensive literature has revealed that there are many aspects which influence the shear characteristics of rock joints in context to saw-tooth types. In most rock engineering problems the shear strength of rock joints vary widely under low affective normal stress levels. This shear strength variation is mostly affected by surface roughness and joint wall strength.
In this paper the results of an experimental investigation carried out under CNL conditions on artificial saw-tooth joints by using a conventional direct shear test machine will be presented. Nine types of saw-tooth joints have been selected for simplicity of modelling to quantify the effect of CNL conditions on joint shear behaviour. Although idealised triangular asperities do not perfectly represent the more irregular or wavy joint profiles in the field, they still provide a simplified basis to understand the effect of varying normal load and shear rate on joint deformation. Based on the results obtained, a new peak shear strength envelope is proposed to model saw-tooth type joints tested under CNL conditions.

\section{SHEAR STRENGTH MODELS FOR ROCK JOINTS}

Several criteria have been proposed in past to identify the strength of a joint. They delineate the state of stress that separates pre-sliding and post-sliding of the joint. The simplest constitutive model for rock joints is perhaps the Coulomb friction law in which the joint behavior is simply characterized by a single value of friction angle.

Patton [4] was the first researcher in rock mechanics to relate the shear behaviour of joints to normal load and roughness. Patton proposed a bilinear envelope that describes fairly well the shear strength of plane surfaces containing a number of regularly spaced teeth of equal dimensions. However, these criteria are not satisfactory for describing the shear behaviour of irregular rock surfaces, for which continuous failure 
envelopes are normally obtained. Again looking at twodimensional saw-tooth profiles, the transition from dilatancy to shearing was studied theoretically and experimentally by Ladanyi and Archambault [5] who approached the problem of joint-shear strength by identifying the areas on the joint surface where sliding and breaking of asperities are most likely to occur. Ladanyi and Archambault's shear-strength model was later reviewed by Saeb [6] in light of the stressdilatancy theory of sand.

Some more complicated joint models appeared later accompanying the development of numerical methods. Notable among them are Barton empirical model [7], AmadeiSaeb's analytical model [8] and Plesha's theoretical model [8]. All of them are two-dimensional models. However, among all the models, Barton's criterion is the only that is currently used in practice. Its approach is based on the choice of the correct value for the roughness parameter, the joint roughness coefficient (JRC). Based on tests carried out on natural rough joints, Barton derived the following empirical equation:

$$
\tau=\sigma_{n} \tan \left(J R C \log _{10}\left(\frac{J C S}{\sigma_{n}}\right)+\phi_{b}\right)
$$

where the JRC (Joint Roughness Coefficient) represents a sliding scale of roughness which varies from approx. 20 to 0 , from the roughest to the smoothest end of the spectrum which was adopted by the International Society for Rock Mechanics as standard profiles for estimating joint roughness and JCS is given by unconfined compression strength $\left(\sigma_{c}\right)$ of the rock (if the joint is unweathered), but may reduce to $0.25 \sigma_{c}$ if the walls are weathered [7].

\section{LABORATORY INVESTIGATIONS}

The aim of laboratory investigation is to establish the likely shearing mechanisms involved when testing artificial rock joints. It is basically impossible to use natural joints for systematic laboratory testing because of the problem of obtaining the same surface geometry for repeated tests. It is always better to match the surface profile of the natural joints using laboratory models. Therefore, to study the frictional response of rock joints, more than $288 \mathrm{CNL}$ direct-shear tests were performed on saw-tooth joints. Direct shear apparatus is suitably designed and fabricated for conducting CNL tests for a maximum normal load of $5000 \mathrm{kN} / \mathrm{m}^{2}$ and a maximum shear load of $50 \mathrm{kN}$ was used in the laboratory programme. It is a constant rate of strain type of equipment and gives 72 rates of deformation, suitable for operation on 415 volts, 50 cycles, three phase AC supply. In this study, the CNL shear tests have been designed in cement-sand cast models with nine variations of inclination angle $(i)$ of saw-tooth joints $\left(i=5^{\circ}, 10^{\circ}, 15^{\circ}, 20^{\circ}\right.$, $25^{\circ}, 30^{\circ}, 35^{\circ}, 40^{\circ}$, and $45^{\circ}$ ) with four variations of normal stress $(0.25,0.5,1.0$ and $1.5 \mathrm{MPa})$ and four variations of shear displacement rate $(0.314,0.502,0.719$ and $1.01 \mathrm{~mm} / \mathrm{min})$.
Based on the experimental results, observations are made to identify mechanisms that have important effects on the deformation behaviour of an artificial rock joint.

In order to have a rock joint with well-defined triangular asperities, the rock joints are simulated in laboratory. The material used for sample preparation was cement, sand and water taken in the 1:2:0.6 by weight. In the testing programme, cement cast models (Fig.1a) were used to represent the idealized rock joints. The specimen is made in two halves of size $10 \mathrm{~cm}$ x $10 \mathrm{~cm} \times 5 \mathrm{~cm}$ each. The basic properties of the model material were determined by conducting uniaxial compression tests on cylindrical specimens with $54 \mathrm{~mm}$ in diameter and $110 \mathrm{~mm}$ in height after a curing period of 28 days. The unconfined compressive strength of the simulated material was $26.85 \mathrm{MPa}$, its tensile strength (determined by Brazilian tests) was about $2 \mathrm{MPa}$ after $24 \mathrm{~h}$. The average Young's modulus is $2548 \mathrm{MPa}$, and the average Poisson's ratio is 0.2. Because of the need for repetitive tests, model rock joints with a regular saw-toothed surface profiles (asperity angle, $i=5^{0}$ to $45^{\circ}$ ) are fabricated (Fig.1a). Nine types of roughness profiles of joint surfaces having various asperity angles and their corresponding asperity heights are shown in Figure $2 \mathrm{a}$.

This direct shear apparatus consists of a shear box which is made in two halves. The top box is $100 \mathrm{~mm}$ long, $100 \mathrm{~mm}$ wide and $50 \mathrm{~mm}$ high, and the bottom box is $100 \times 100 \times 50$ $\mathrm{mm}$. For measuring the shear load a high sensitivity proving ring of $50 \mathrm{kN}$ capacity was used. Shear and normal displacements were measured by two dial gauges in each direction. Fig. 1b shows the testing apparatus.

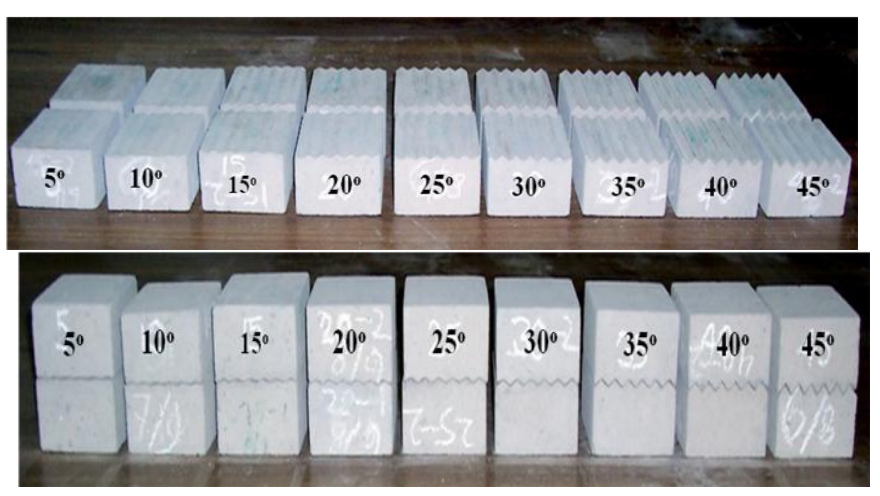

Fig -1a: Photographs of prepared saw-tooth joint specimens 


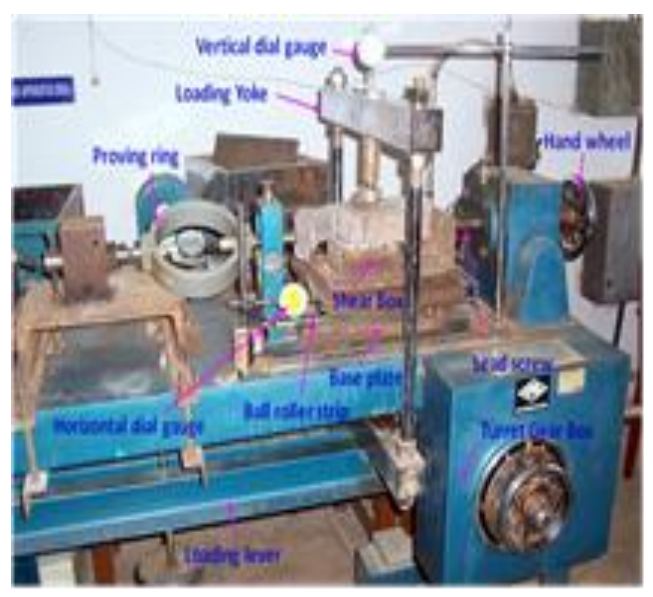

Fig -1b: Shear apparatus suitably designed and fabricated for conducting CNL tests.

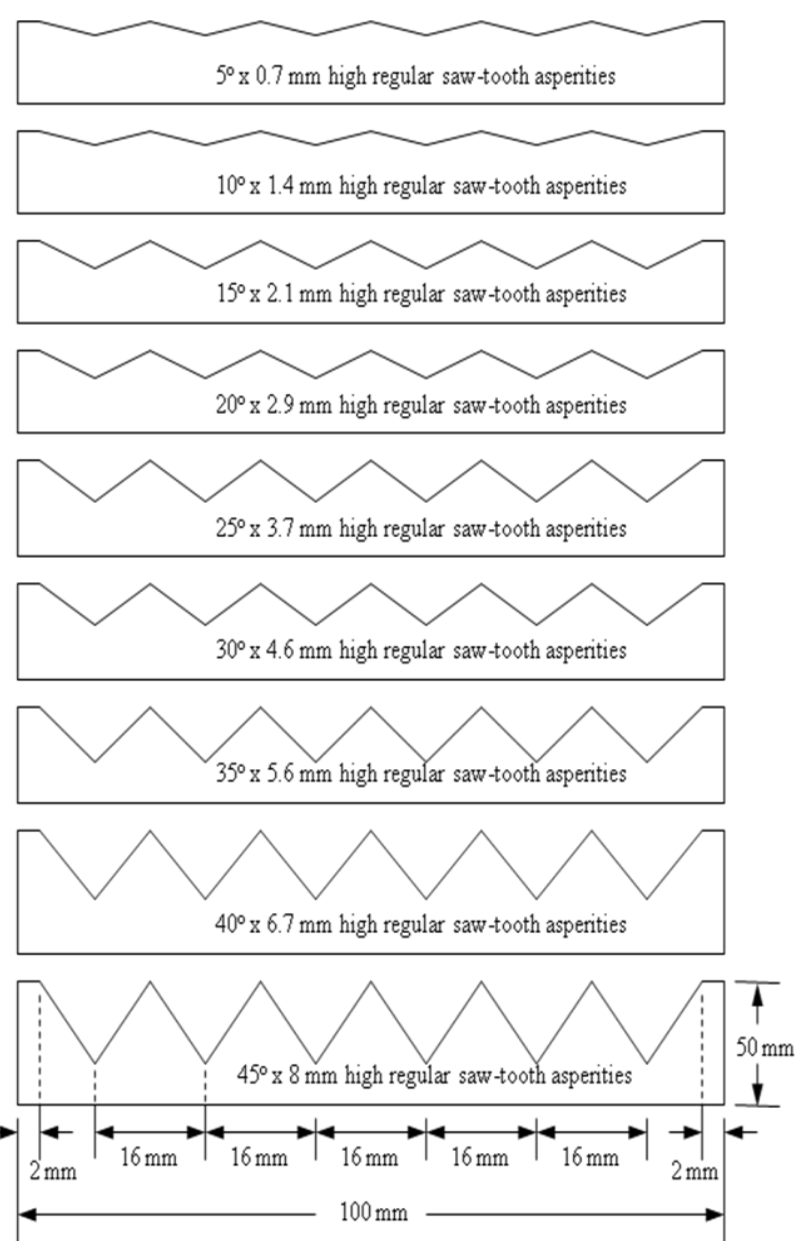

Fig -2a: Schematic diagram of various roughness profiles used in direct shear testing (not scaled).

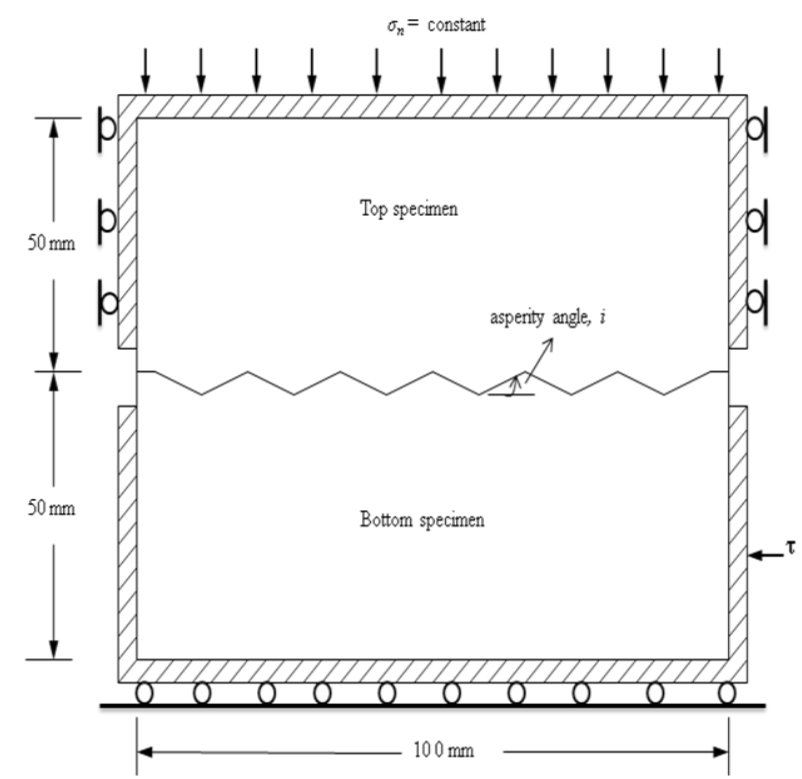

Fig -2b: Schematic diagram of the CNL shear test for an artificial joint specimen with regular saw-tooth asperities.

\section{EXPERIMENTAL RESULTS}

The direct shear tests were performed to study the behaviour of the saw-tooth joint samples during small shear displacements. Variations in shear strength in CNL loading conditions under different shearing rates, varied joint surfaces (joint asperity angles) and normal stresses were studied. More than 200 interlocked (mating) jointed block samples were tested in the laboratory under constant normal loading conditions. The results of some of the tests performed will be presented and discussed in this paper.

The shear responses and actual shear failure modes of each joint were observed during different stages of laboratory experiments. During shearing, shear load together with the dilation and horizontal displacements are recorded. In this paper Type 1 to Type 9 joints are defined depending on asperity angle $i=5^{\circ}$ to $45^{\circ}$. The normal stresses $\sigma_{n}<1.0$ $\mathrm{MPa}$ (e.g., 0.25 and $0.5 \mathrm{MPa}$ ) and $\sigma_{n} \geq 1.0 \mathrm{MPa}$ (e.g., 1.0 and 1.5 MPa) are defined as low normal stresses and high normal stresses respectively. The asperity angles $i=5^{\circ}$ to $20^{\circ}$ and $i=25^{\circ}$ to $45^{\circ}$ are defined as low asperity angles and high asperity angles respectively.

\subsection{Effect of Normal Load on Shear Strength Characteristics}

The shear behavior of a rock joint depends mainly on the asperity angle and the stress ratio of $\sigma_{n} / \sigma_{c}$. The normal stress distribution carried by each asperity is mainly dependent upon the asperity angle and the asperity deformation property. Two 
typical shear behaviors of joint models with tooth-shaped asperities were observed during the experiments. For an asperity angle $i=15^{\circ}$ : (1) Slide-up mode: At lower normal stress, a slide-up behavior takes place and the shear stressdisplacement curve shows a more ductile behavior (Fig. 3 (a)). The shear stress initially causes elastic deformation of the asperity material up to about $1 \mathrm{~mm}$, and no dilation is recorded. The dilation curve, which always traces the new surface of the asperity during shearing, is only a little lower than the initial asperity plane and reveals slight damage on the asperity. For an asperity angle $i=40^{\circ}$ : (2) Shear off mode: At higher normal stress, a brittle shear behavior (Fig. 3 (b)), shown in the shear stress-displacement curve with a sudden stress-drop after peak stress, accompanied by the asperity fracture was observed. A smaller dilation angle recorded in the dilation curve reveals severe damage or shear-off on the asperity.

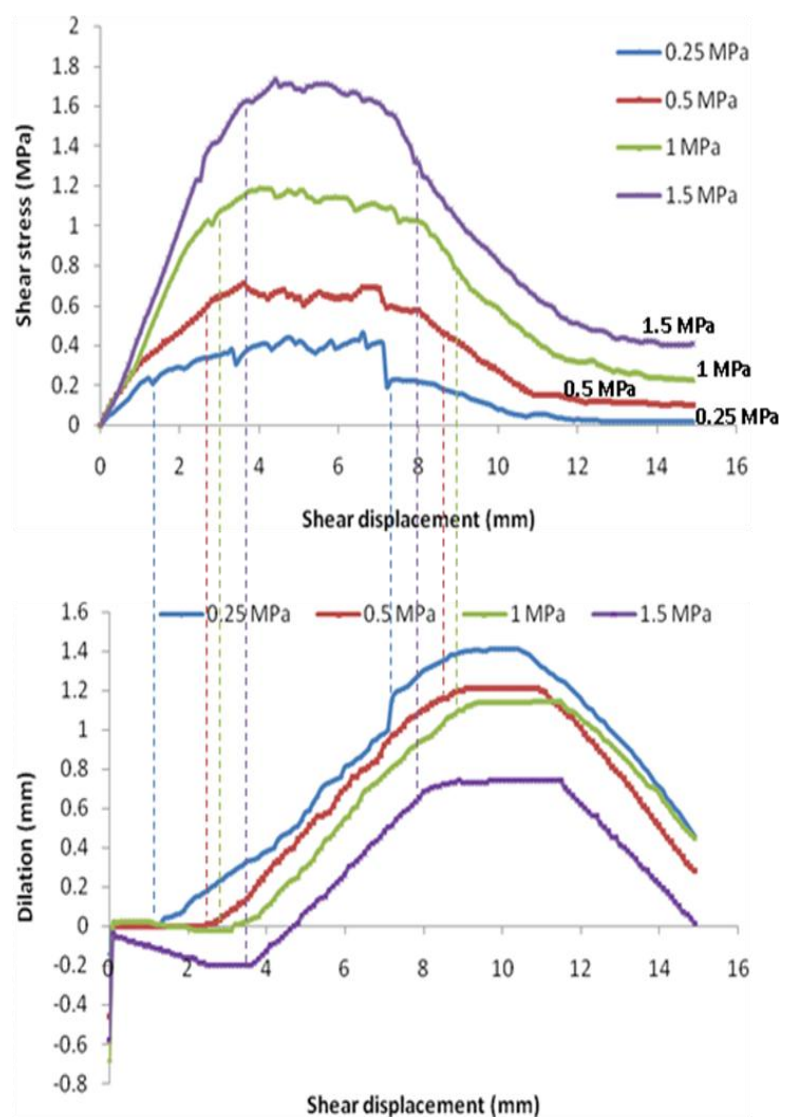

Fig -3a: Shear stress-shear displacement and dilation curves at $0.502 \mathrm{~mm} / \mathrm{min}$ shear rate, Slide-up mode (asperity angle $i=$ $15^{\circ}$ )

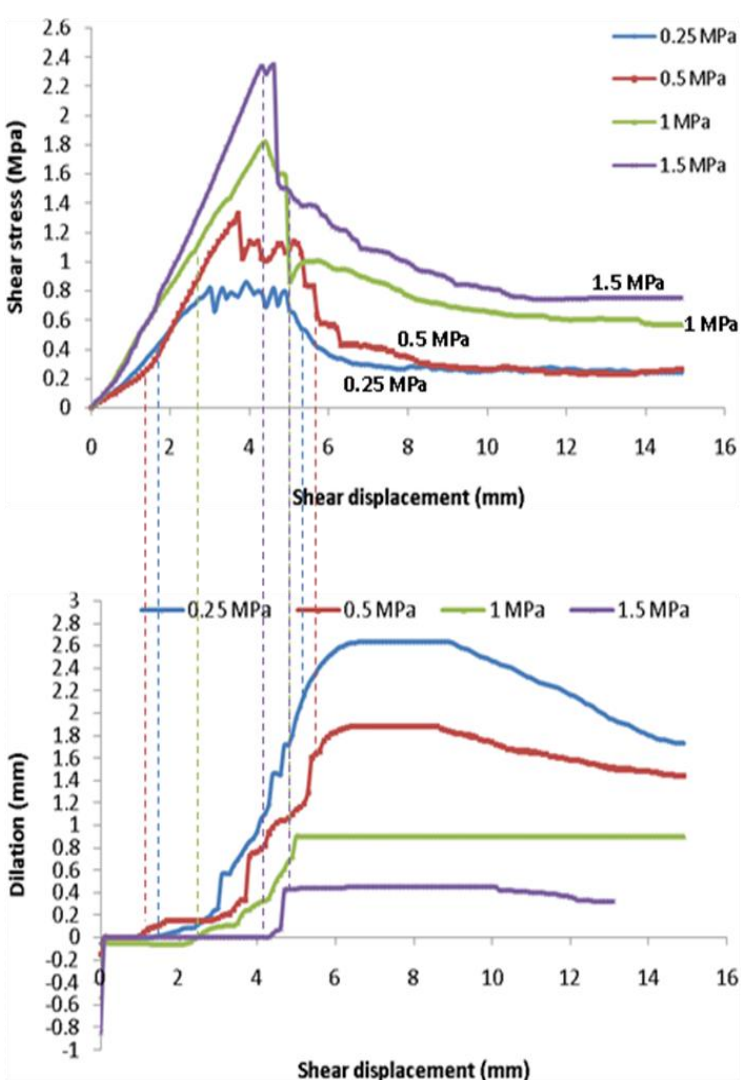

Fig -3b: Shear stress-shear displacement and dilation curves at $0.502 \mathrm{~mm} / \mathrm{min}$ shear rate, Shear-off mode (asperity angle $i=$ $40^{\circ}$ )

\subsection{Shear-Strength Envelopes for Saw-Toothed}

\section{Model Joints}

This section presents the comparison of proposed shear strength envelopes with Barton's peak shear strength envelope for various saw-toothed joints based on laboratory experimental test data. Joint roughness has an essential influence on the shear behaviour of rock joints. The effect of surface roughness on shear strength is found to be more pronounced for relatively lower normal stress values. By testing saw-tooth joints with various asperity angles at lower normal stress values, it is found that shearing occurs by overriding of the asperities. At higher level of normal stress, the asperities begin to be sheared-off for nominal shear displacements. It is found that shear resistance of saw tooth jointed samples increases with asperity angle up to $30^{\circ}$ and then it falls with increasing angle. This implies that for a given specimen the maximum shear strength achieves for a specified $\sigma_{n}$ when the asperity angle is close to $30^{\circ}$. Barton's peak shear strength envelope has been compared with the experimental test data. The JRC values are back-calculated from the peak shear strength of the experimental test data following the Barton's formula (equation 1). It was found that JRC value is 
7 for $i=5^{\circ}$ and increases to 20 at $i=20^{\circ}$ (Fig. 5 (a)). If the asperity angle is greater than $20^{\circ}$, Barton's equation (given in equation 1) underestimates the shear strength value for a given $\sigma_{n}$ (Fig. 4). It implies that progressive failure of asperities and shear resistance provided by the broken asperities cannot be modeled with Barton's equation as given in Equation 1.

It is envisaged that for higher asperity angle $\left(i>20^{\circ}\right)$ an additional shear resistance occurs once the asperities is broken off from the joint surfaces during the shearing process, just as mentioned by "shear area ratio" and "degree of interlocking" in joint model proposed by Ladyani and Archambault [7]. In their shear strength envelope, they have considered the factors as shear area ratio giving the proportion of joint area sheared through the asperities $\left(a_{s}\right)$ and "degree of interlocking" by the concept of progressive failure and intact shearing through asperities. Small shear displacement may be allowed in the process of crushing or riding over the broken asperities since these broken asperities may not be fixed in a place. On the other hand, "degree of interlocking" factor contributes to the increase in shear strength as overriding of asperities during shearing process. As Barton's shear strength envelope does not consider these two factors, the shear stress values obtained from Equation 1 is somewhat lower than the experimental values. Under the present experimental conditions this seems to be a probable reason for increase in the shear resistance and hence Barton's envelope underestimates the shear strength of saw-tooth jointed samples at higher asperity angles. In order to combine both these two factors into Barton's envelope an additional friction angle due to asperities degradation during shearing is introduced. This angle is termed as $\varphi_{f}$, and the following shear strength envelope is proposed by modifying the Barton's equation to fit the experimental results.

$$
\tau=\sigma_{n} \tan \left(J R C \log _{10}\left(\frac{J C S}{\sigma_{n}}\right)+\phi_{\mathrm{b}}+\phi_{f}\right)
$$

Where, $\phi_{f}=$ additional friction angle due to asperities degradation during shearing.

$i_{e}=J R C \log _{10}\left(J C S / \sigma_{n}\right)$ is the effective roughness angle.

$\sigma_{n}$ is the effective normal stress (MPa).

JRC is the roughness coefficient on a scale of roughness from 0 to 20 .

JCS is the joint wall compressive strength of the rock (MPa). $\phi_{b}$ is the basic friction angle $\left({ }^{\circ}\right)$.

The values of $\phi_{f}$ are obtained from trial and error basis by minimising the error to fit the experimental results. The predicted values from Equation 2 for saw-tooth jointed samples were compared to those calculated using Barton's peak-shear-strength criterion (Equation 1). The comparison shows that the values obtained with Equation 2 gives a better fit to the experimental data. The variation of peak shear strength and corresponding normal stress for saw-toothed model joints are shown in Figures $4 \mathrm{a}$ to $4 \mathrm{i}$.

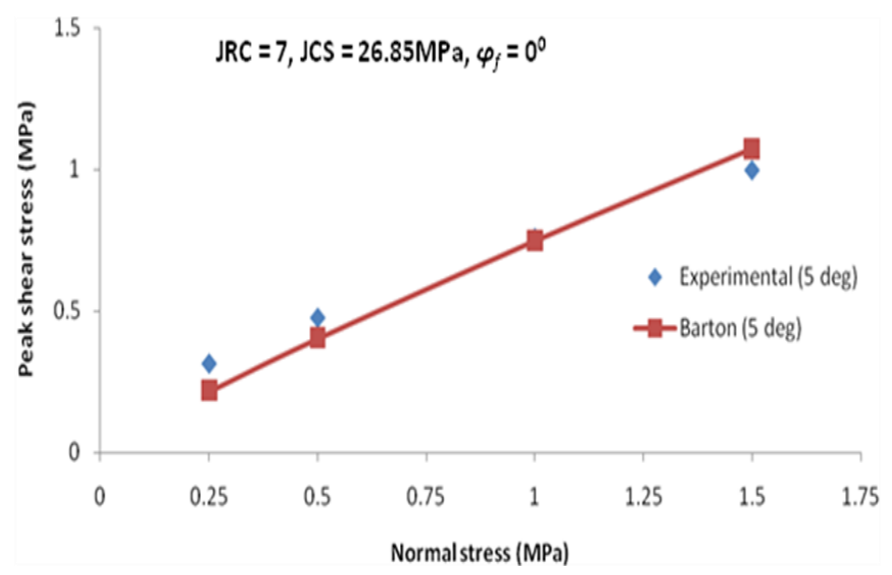

(a)

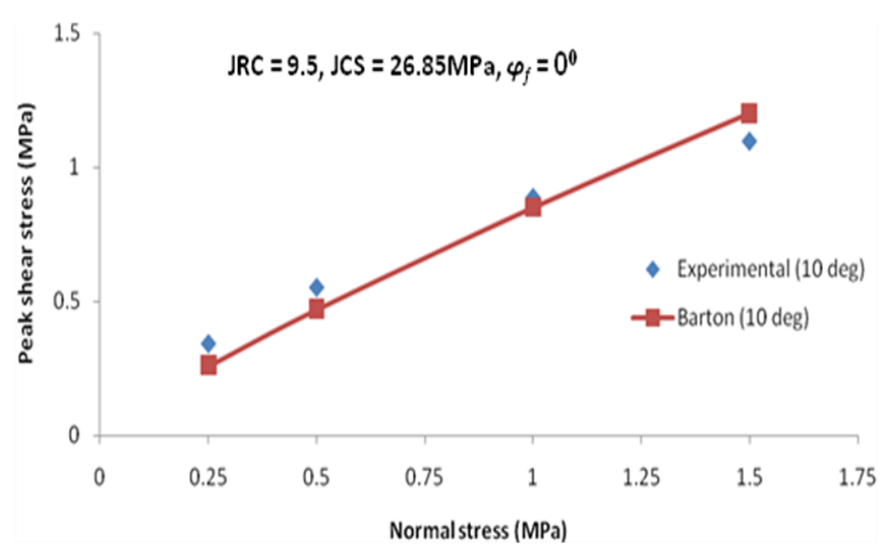

(b)

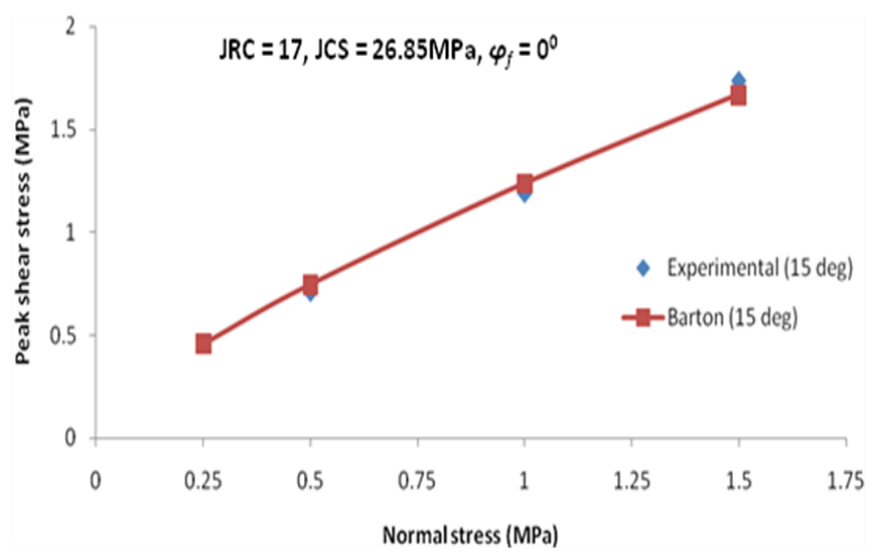

(c) 


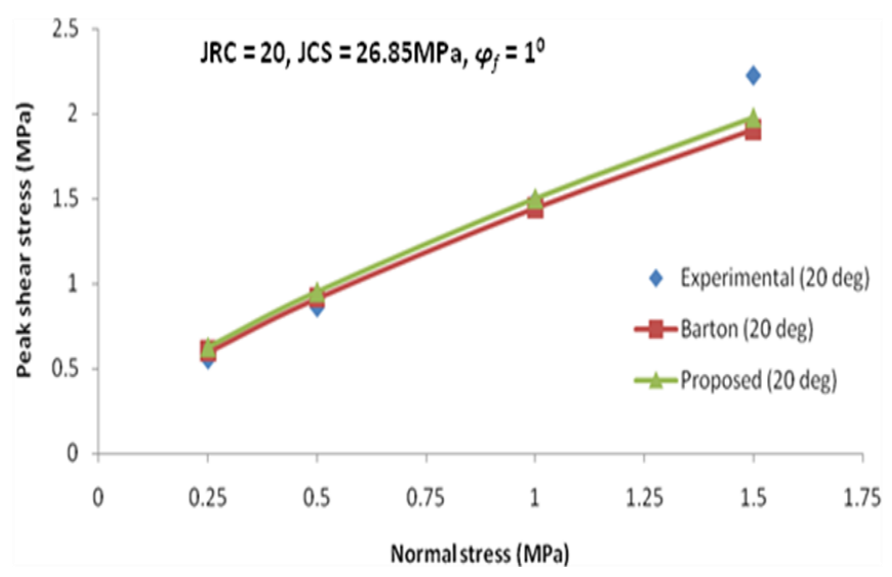

(d)

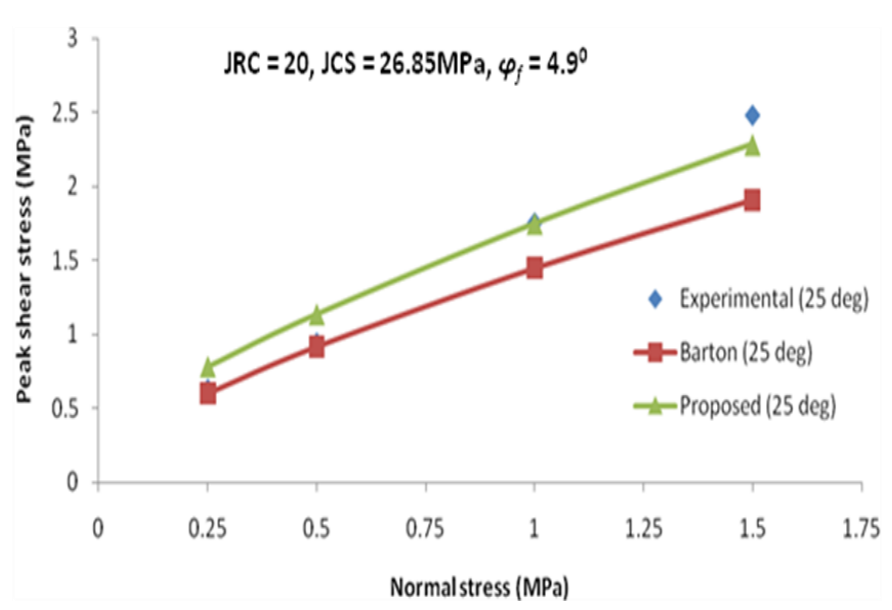

(e)

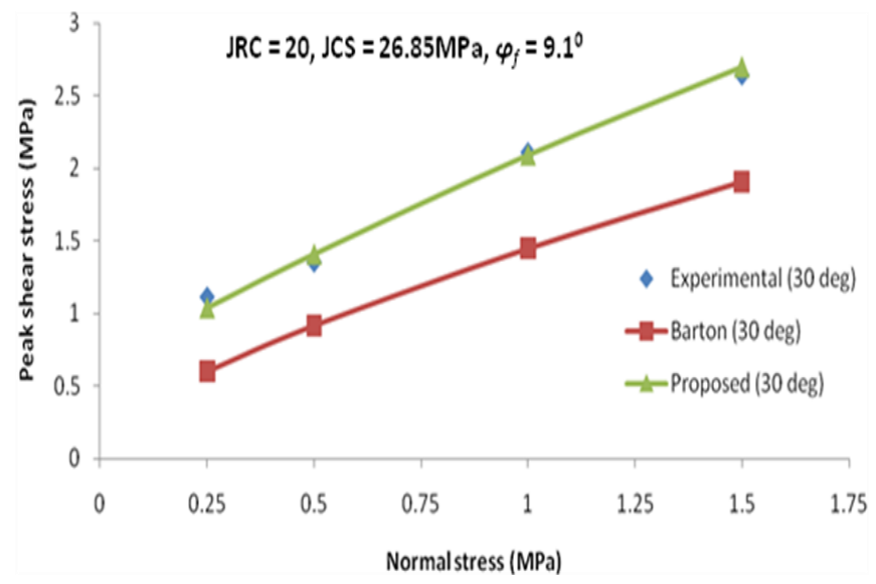

(f)

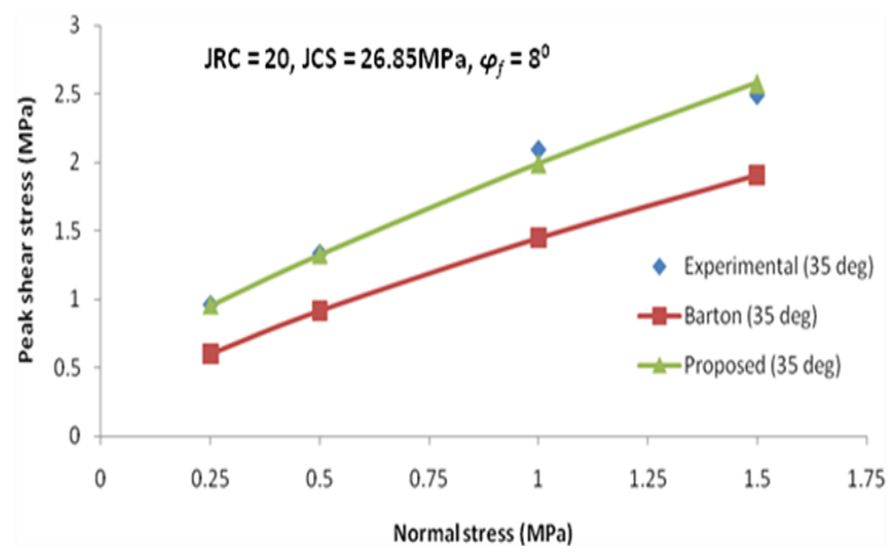

$(\mathrm{g})$

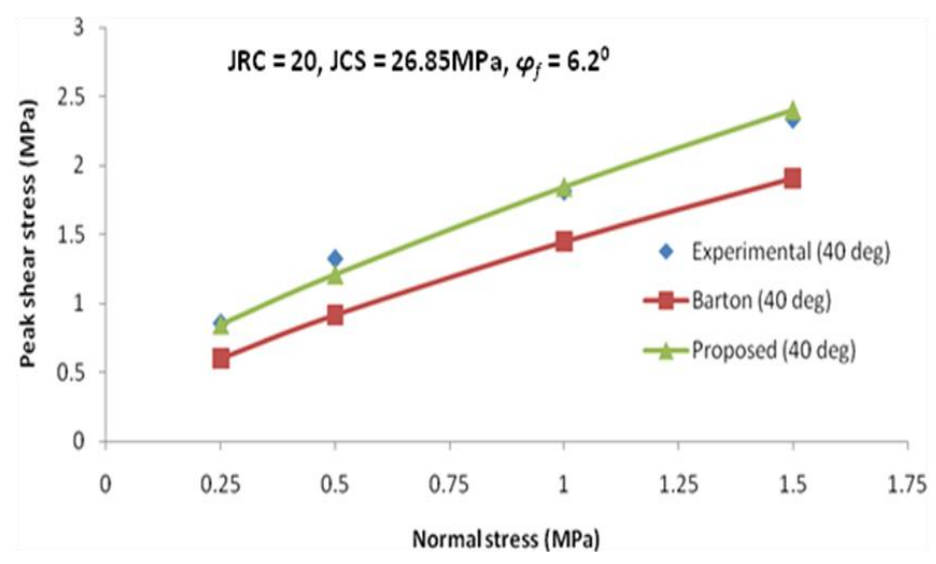

(h)

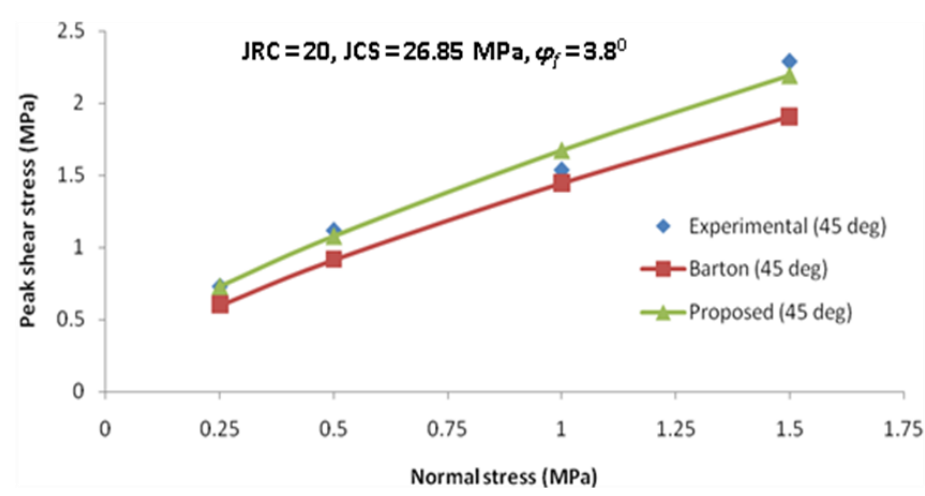

(i)

Figs. 4a to 4i: Proposed strength envelopes for saw-tooth joints $\left(i=5^{\circ}, 10^{\circ}, 15^{\circ}, 20^{\circ}, 25^{\circ}, 30^{\circ}, 35^{\circ}, 40^{\circ}\right.$ and $\left.45^{\circ}\right)$ compared to Barton's criterion. 


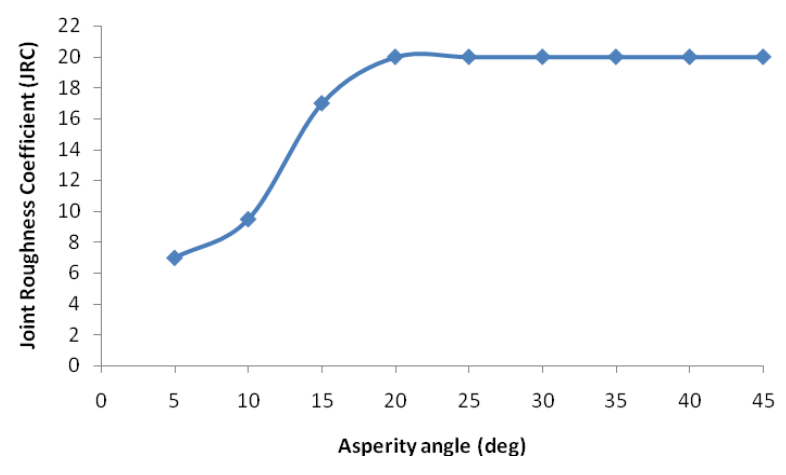

Fig. 5: (a) Joint Roughness Coefficient vs Asperity angle

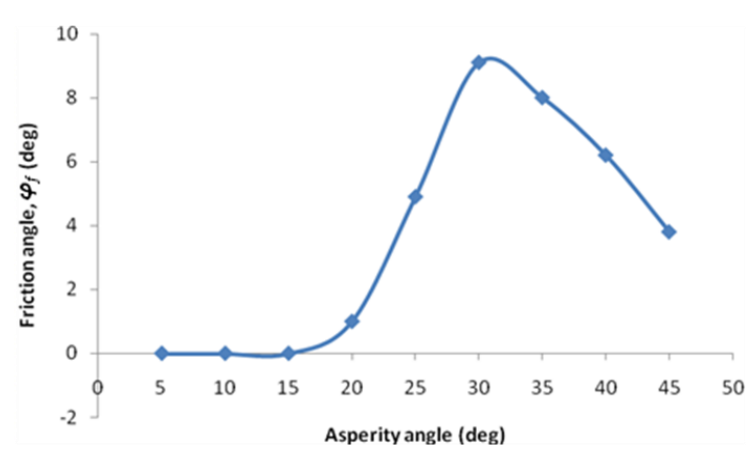

Fig. 5: (b) Friction angle $\left(\varphi_{f}\right)$ vs Asperity angle

Fig. 5 (a) plots the JRC values for different asperity angles. It shows that for $i \geq 20^{\circ}$, JRC remains at 20. In addition, $\phi_{f}$ has been plotted with angle $i$ in Fig. 5 (b). It depicts that $\phi_{f}$ is maximum $\left(9.1^{\circ}\right)$ at $i=30^{\circ}$ and then it falls as the asperity angle increases.

\section{CONCLUSIONS}

This paper discusses a study of the variation in shear strength of saw-tooth model joints in different constant normal loading conditions. The following main conclusions may be drawn from this investigation:

1. At higher normal stresses, the nature of shear stressdisplacement tends to be more brittle and the asperity failure was noticed to begin with the frontal asperities and followed a progressive failure rather than simultaneous failure of the asperities in contact.

2. It was observed from the test results that the peak shear stress increases with the increase in normal stress. The brittleness of the shear stress-shear displacement response also increases with increasing normal stress.

3. With an increased normal stress and an asperity angle of saw-tooth shaped joints, a progressive degradation of asperities occurred which increases peak shear strength and reduces dilation zone. It may be noted that joints with increasing asperity height causes greater degree of dilation with increased shear resistance for the same levels of normal stress.

4. It was observed from the test results, that in low-angled joints, the peak shear stress reached at a greater displacement and in the high-angled joints the peak shear stress reached at a smaller displacement. This may be attributed to the high stress concentration around the asperities, which cause enhanced surface degradation, thereby shearing at smaller horizontal displacements.

5. The comparison of predicted values from the proposed shear strength criterion with that of Barton's criterion shows that the values obtained with proposed shear strength criterion results in a better fit to the experimental data. In order to improve the models, more investigations should be carried out on real rock joint samples.

\section{REFERENCES}

[1]. Hoek, E., and E.T. Brown. (1980). Underground excavations in rock. The Institution of Mining and Metallurgy. London, U.K.

[2]. Barton, N.R. (1986). Deformation phenomena in jointed rock. Geotechnique, Vol. 36, No. 2, pp. 147-167.

[3]. Hoek, E. (1983). Strength of jointed rock masses. Geotechnique, Vol. 33, No. 3, pp. 187-223.

[4]. Goodman, R.E., and G.H. Shi. (1985). Block Theory and Its Application in Rock Engineering. Englewood Cliffs, NJ, Prentice-Hall.

[5]. Bandis, S., Lumsden, A.C. and Barton, N.R. (1981). Experimental studies of scale effects on the shear behaviour of rock joints. Int. J. Rock Mech. Min. Sci. and Geomech. Abstr., Vol. 18, pp. 1-21.

[6]. Patton, F.D. (1966). Multiple modes of shear failure in rocks. Proc. 1st Cong, Int. Soc. Rock Mech., Lisbon, Vol. 1, pp. 509-513.

[7]. Ladanyi, B. and Archambault, G. (1970). Simulation of shear behavior of jointed rock mass. Proc. 11th Symp. on Rock Mechanics: Theory and Practice, AIME, New York, pp. 105-125.

[8]. Saeb, S. (1990). A variance on Ladanyi and Archambault's shear strength criterion. Rock Joints, Barton, (ed. Stephansson), Balkema (Rotterdam), pp. 701-705.

[9]. Barton, N. and Choubey, V. (1977). The shear strength of rock joints in theory and practice. Rock Mechanics, Vol. 10, pp. 1-54.

[10]. Saeb, S. and Amadei, B. (1992). Modelling rock joints under shear and normal loading. Int. J. Rock Mech. Min. Sci. and Geomech. Abstr., Vol. 29, No. 3, pp. 267-278.

[11]. Plesha, M.E. (1987). Constitutive models for rock discontinuities with dilatancy and surface degradation. Int. J. Numer. Anal. Methods Geomech. Vol. 11, pp. 345-362.

[12]. Bandis, S.C., Lumsden, A.C. \& Barton, N.R. (1983). Fundamentals of rock joint deformation. Int. J. Rock Mech. Min. Sci. and Geomech. Abstr., Vol. 20, No. 6, pp. 249-268. 
[13]. Barton, N. (1973). Review of a new shear strength criterion for rock joints. Engineering geology, Vol. 7, pp. 287332.

[14]. Barton, N. (1974). Review of shear strength of filled discontinuities in rock. Publication No. 105. Oslo, Norwegian Geotechnical Institute, p. 38.

[15]. Barton, N. (1976). Rock mechanics review, the shear strength of rock and rock joints. Int. J. Rock Mech. Min. Sci. and Geomech. Abstr., Vol. 13, pp. 255-279.

[16]. Barton, N.R. (1971). A relationship between joint roughness and joint shear strength. Proc. of Int. Symp. on Rock Mech. Rock Fracture, Nancy, France, p. 1-8.

[17]. Crawford, A.M. and Curran, J.H. (1981). The influence of shear velocity on the frictional resistance of rock discontinuities. Int. J. Rock Mech. Min. Sci. and Geomech. Abstr., Vol. 18, pp. 505-515.

[18]. Goodman, R.E. (1970). The deformability of joints. Determination of the insitu modulus of deformation of rocks. American Society for Testing and Materials, No. 477, pp. 174196.

[19]. Goodman, R.E., and Ohnishi, Y. (1973). Undrained shear testing of jointed rock. Rock Mechanics, Vol. 5, pp. 129149.

[20]. Haberfield, C.M. and Johnston, I.W. (1994). A mechanistically based model for rough rock joints. Int. J. Rock. Mech. Min. Sci. and Geomech. Abstr., Vol. 31, No. 4, pp. 279-292.

[21]. Hoek, E. (1983). Strength of jointed rock masses. Geotechnique, Vol. 33, No. 3, pp. 187-223.

[22]. Indraratna, B., Haque, A. and Aziz, N. (1998). Laboratory modelling of shear behavior of soft joints under constant normal stiffness condition. Geotechnical and Geological Engineering, Vol. 16, pp. 17-44.

[23]. Jing, L., Stephansson, O. and Nordlund, E. (1993). Study of rock joints under cyclic loading conditions. Rock Mech. and Rock Eng., Vol. 26, pp. 215-232.

[24]. Kodikara, J.K. and Johnston, I.W. (1994). Shear behaviour of irregular triangular rock concrete joints. Int. J. Rock Mech. Min. Sci. and Geomech. Abstr., Vol. 31, No. 4, pp. 313-322.

[25] Siedel, J.P. and Haberfield, C.M. (1995b). Towards an understanding of joint roughness, Rock Mech. Rock Eng., Vol. 28, No. 2, pp. 69-92.

\section{BIOGRAPHIES}

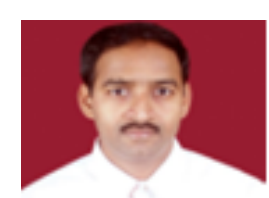

Dr. G. Budi is working as Assistant Professor in the Department of Mining Engineering, Indian School of Mines, Dhanbad. His areas of expertise include rock mechanics and ground control, numerical modelling and tunneling \& underground space technology.

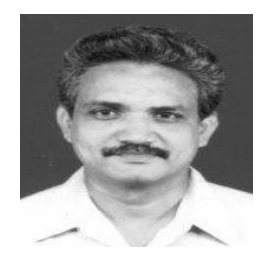

Prof. K.U.M. Rao is working as Professor and Head in the Department of Mining Engineering, IIT Kharagpur. His areas of expertise include rock mechanics, mine development, back filling of mine voids and underground metal mining.

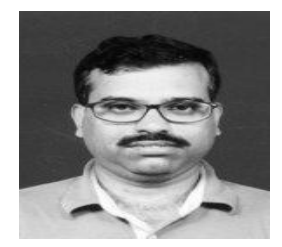

Prof. Debasis Deb is working as Professor in the Department of Mining Engineering, IIT Kharagpur. His areas of expertise include rock mechanics, numerical modelling, ground control and mine design. 